\title{
Analisis Investasi Saham dalam Sistem Hukum Ekonomi Syariah: Sebuah Syarah Hadis Pendekatan Isu Kontemporer
}

\author{
Novi Nur Sholihat \\ Jurusan Ilmu Al-Qur'an dan Tafsir, Fakultas Ushuluddin \\ UIN Sunan Gunung Djati Bandung, Indonesia \\ novinursholihat02@gmail.com
}

\begin{abstract}
This study aims to analyze the hadith about stock investment in Islam. This study uses a qualitative approach that emphasizes literature study through the takhrij and syarah hadith methods with contemporary analysis. The results of this study found that the quality status of the investment hadith was assessed as hasan li ghairihi, in the sense of maqbul and ma'mul bih for Muslim practice. The conclusion of this study is that the hadith of the Prophet Muhammad regarding stock investment in Islam is a recommended activity, because investment activities have been carried out by the Prophet Muhammad since he was young until before the apostleship. Unless prohibited activities are found in investment activities, both objects and procedures, the investment is prohibited. This study recommends that further research be carried out through collaboration between enthusiasts of hadith science and business economics to research related to stock investment in terms of objects and processes if you want to invest in stocks in accordance with Islamic teachings.
\end{abstract}

Keywords: Hadith, Investment, Islam, Stock

\begin{abstract}
Abstrak
Penelitian ini bertujuan untuk menganalisis hadis tentang investasi saham dalam Islam. Penelitian ini menggunakan pendekatan kualitatif yang ditekankan pada studi pustaka melalui metode takhrij dan syarah hadis dengan analisis kontemporer. Hasil penelitian ini menemukan bahwa status kualitas hadis investasi dinilai hasan li ghairihi, dalam arti maqbul dan ma'mul bih bagi amalan muslim. Kesimpulan penelitian ini adalah hadis Nabi Saw tentang investasi saham dalam Islam merupakan kegiatan yang dianjurkan, karena kegiatan investasi sudah dilakukan oleh Nabi Muhammad Saw sejak muda sampai menjelang kerasulan. Kecuali apabila ditemukan kegiatan terlarang dalam kegiatan investasi, baik objek maupun prosedur, maka investasi tersebut dilarang. Penelitian ini merekomendasi agar dilakukan penelitian lebih
\end{abstract}


Jurnal Riset Agama, Volume 1, Nomor 1 (April 2021): 157-166

Novi Nur Sholihat / Analisis Investasi Saham dalam Sistem Hukum Ekonomi

Syariah: Sebuah Syarah Hadis Pendekatan Isu Kontemporer

lanjut melalui kolaborasi antara peminat ilmu hadis dan ilmu ekonomi bisnis untuk meneliti terkait investasi saham dari segi objek dan proses jika ingin berinvestasi saham sesuai dengan tuntunan ajaran Islam.

Kata Kunci: Hadis, Investasi, Islam, Saham

\section{Pendahuluan}

Investasi dan jual beli saham masih dianggap sebagai salah satu kegiatan yang spekulatif dan dilarang agama karena sama dengan perjudian bagi masyarakat awam (Hartati, 2021). Investasi merupakan hal yang sudah harus dipersiapkan untuk masa depan, walaupun menurut ajaran agama kita tidak akan tahu apa yang akan terjadi dimasa yang akan datang tetapi kita harus tetap berikhtiar (Selasi, 2018). Investasi merupakan kegiatan yang dianjurkan dalam pandangan Islam. Hal ini karena kegiatan investasi sudah dilakukan oleh Nabi Muhammad Saw. sejak muda sampai menjelang kerasulan. Selain itu akan tercapainya mashlahah multiplayer effect, di antaranya tercipta lapangan usaha dan lapangan pekerjaan, menghindari dana mengendap dan agar dana tersebut tidak berputar di antara orang kaya saja (Pardiansyah, 2017). Oleh karena itu, meninjau fenomena investasi saham tersebut penulis tertarik untuk mengetahui lebih dalam melakukan investasi saham menggunakan teori ilmu hadis berikut syarah-nya.

Sejumlah ahli telah melakukan penelitian mengenai investasi saham sebagaimana dalam tinjauan pustaka ini. Di antaranya Selasi, D. (2018), "Ekonomi Islam: Halal dan Haramnya Berinvestasi Saham Syaria," Jurnal Ekonomi Syariah dan Bisnis. Penelitian ini menggunakan metode penelitian kepustakaan. Hukum jual beli saham dan bursa efek dalam Islam dan juga menurut MUI adalah halal dibuktikan dengan adanya fatwafatwa MUI sebagai pendukungnya. Kesimpulannya selama metode transaksinya dilakukan sesuai tuntutan syariah dan jenis saham yang dibeli dari perusahaan yang menjalankan bisnisnya secara halal pula maka semua transaksi di pasar modal termasuk saham adalah halal (Selasi, 2018). Arrazaq, N.A. (2020), "Investasi Syariah dalam Rangka Menegakan Prinsip Syariah," Journal of Islamic Law Studies. Penelitian ini menggunakan metode yuridis normative. Dasar hokum untuk muamalah adalah boleh sampai ada dalil yang mengharamkannya. Kesimpulannya investasi berarti kita sedang menanam modal untuk mencari keuntungan dengan akadakad syariah maka ini termasuk kedalam perbuatan muamalah dimana perbuatan ini adalah boleh untuk dilakukan sampai ada dalil yang mengharamkannya (Arrazaq, 2020). Pardiansyah, E. (2017), "Investasi dalam Perspektif Ekonomi Islam: Pendekatan Teoritis dan Empiris," Economi: Jurnal Ekonomi Islam. Investasi merupakan komitmen atas sejumlah dana atau 
Jurnal Riset Agama, Volume 1, Nomor 1 (April 2021): 157-166

Novi Nur Sholihat / Analisis Investasi Saham dalam Sistem Hukum Ekonomi

Syariah: Sebuah Syarah Hadis Pendekatan Isu Kontemporer

sumber daya lainnya yang dilakukan dengan tujuan memperoleh sejumlah keuntungan dan kemaslahatan di masa yang akan datang. Investasi merupakan kegiatan yang sangat dianjurkan dalam Islam bahkan benih dasarnya sudah ada di dalam Al-Qur'an (QS. al-Baqarah [2]: 261; QS. alNisa [4]: 9; QS. Yusuf [12]: 46-49; QS. Luqman [31]: 34 dan QS. al-Hasyr [59]: 18) dan diperkuat oleh sunnah Nabi Muhammad Saw. yang pernah menjadi mitra investor sekaligus pelaku bisnis. Kesimpulannya dasar prinsip investasi pada dasarnya adalah boleh dilakukan sampai ada dalil yang melarangnya, yaitu apabila ditemukan kegiatan terlarang dalam suatu kegiatan bisnis, baik objek maupun caranya (prosesnya), yaitu kegiatan yang mengandung gharar, maysīr, riba, tadlīs, talaqqī rukbān, taghrīr, ghabn, darar, risywah, maksiat dan zalim. Untuk melihat suatu entitas menjalankan kegiatan usahanya berdasarkan prinsip syariah atau tidak dapat dilihat dengan metode screening syariah yaitu, pertama melihat bisnis yang dijalankannya, baik itu proses maupun produk barangnya; kedua, menganalisa rasio pendapatan non-halal dan rasio utang berbasis bunga terhadap jumlah aset yang dimiliki (Pardiansyah, 2017).

Penelitian sebelumnya mengenai investasi saham dalam Islam yang telah diuraikan pada tinjauan pustaka sangat berkontribusi terhadap penyusunan kerangka berpikir ini. Investasi saham dalam Islam halal dibuktikan dengan adanya fatwa-fatwa MUI sebagai pendukungnya. Selama metode transaksinya dilakukan sesuai tuntutan syariah dan jenis saham yang dibeli dari perusahaan yang menjalankan bisnisnya secara halal pula maka semua transaksi di pasar modal termasuk saham adalah halal (Selasi, 2018). Bahwa dalam sumber-sumber hukum Islam yaitu AlQur'an, hadis, fiqh, ijma' ulama, dan pendapat ulama ditegaskan bahwa jual beli saham hukumnya halal (Hartati, 2021). Investasi berarti kita sedang menanam modal untuk mencari keuntungan dengan akad-akad syariah maka ini termasuk kedalam perbuatan muamalah dimana perbuatan ini adalah boleh untuk dilakukan sampai ada dalil yang mengharamkannya (Arrazaq, 2020). Investasi merupakan komitmen atas sejumlah dana atau sumber daya lainnya yang dilakukan dengan tujuan memperoleh sejumlah keuntungan dan kemaslahatan di masa yang akan datang. Investasi merupakan kegiatan yang sangat dianjurkan dalam Islam bahkan benih dasarnya sudah ada di dalam al-Qur'an dan diperkuat oleh sunnah Nabi Muhammad Saw. yang pernah menjadi mitra investor sekaligus pelaku bisnis (Pardiansyah, 2017). Hadis adalah segala apapun yang berasal dari Nabi shallallauhu 'alaihi wasallam (Darmalaksana \& Qomaruzzaman, 2020). Hadis merupakan sumber hukum Islam kedua setelah Al-Qur'an yang memiliki peranan penting dalam Islam (Ridwan, Umar, \& Ghafar, 2021). Takhrij adalah suatu metode untuk mengeluarkan hadis dari kitab hadis untuk dilakukan penelitian terhadap kualitas ke-shahih-annya yang 
Jurnal Riset Agama, Volume 1, Nomor 1 (April 2021): 157-166

Novi Nur Sholihat / Analisis Investasi Saham dalam Sistem Hukum Ekonomi

Syariah: Sebuah Syarah Hadis Pendekatan Isu Kontemporer

mencakup shahih, hasan, dan dha'if (Darmalaksana, 2021a). Syarah adalah penjelasan mengenai hadis, adapun syarah yang beraitan dengan hadis adalah usaha menafsirkan makna yang berada dibalik teks hadis (Darmalaksana, 2020c). Berdasarkan pencarian terhadap hadis yang ada kaitannya dengan investasi saham dalam Islam melalui Ensiklopedia Hadis Kitab 9 Imam (Saltanera, 2015) ditemukan beberapa hadis, akan tetapi hadis yang akan penulis bahas pada penelitian ini hanyalah hadis riwayat alKhamsah dari 'Amr bin Syu'aib dari ayahnya dari kakeknya, hadis ini dinyatakan shahih oleh Tirmidzi, Ibnu Khuzaimah, dan Hakim. Setelah status keshahihan hadis diketahui selanjutnya dilakukan syarah untuk menjelaskan makna yang terkandung dalam teks hadis (Darmalaksana, 2021a). Oleh karena itu, penelitian ini akan membahas "Hadis yang berkaitan dengan investasi saham" melalui metode takhrij dan syarah menggunakan pendekatan ilmu yang sejalan dan relevan dengannya.

Berdasar pada pemaparan di atas, penulis berupaya untuk menyusun formula penelitian yang terdiri dari rumusan masalah penelitian, petanyaan utama penelitian, dan tujuan penelitian (Darmalaksana, 2020a). Rumusan masalah dalam penelitian ini adalah terdapat syarah hadis terkait dalil investasi saham dalam Islam. Pertanyaan utama penelitian ini adalah bagaimana syarah hadis tentang dalil investasi saham dalam Islam. Adapun pertanyaan penelitian secara terperinci yakni bagaimana teks hadis tentang investasi, bagaimana kualitas hadis tentang investasi dan bagaimana syarah hadis tentang dalil investasi saham dalam Islam. Tujuan penelitian ini yaitu membahas syarah hadis tentang dalil investasi saham dalam Islam. Penelitian ini diharapkan bermanfaat bagi masyarakat yang ingin mengetahui investasi saham dalam Islam.

\section{Metode Penelitian}

Penelitian ini menggunakan pendekatan kualitatif yang ditekankan pada studi pustaka, dengan kata lain peneliti tidak turun langsung ke lapangan (Darmalaksana, 2020b). Penelitian ini menggunakan metode takhrij dan syarah (Darmalaksana, 2020d) terhadap hadis yang berkaitan dengan investasi saham melalui analisis kontemporer (Darmalaksana, 2020c).

\section{Hasil dan Pembahasan Penelitian}

Hasil penelitian dan pembahasan disajikan dalam beberapa hal.

\section{Teks Hadis Investasi Saham dalam Islam}

Berdasarkan pencarian hadis tentang investasi melalui aplikasi Ensklopedia Hadis Kitab 9 Imam (Saltanera, 2015), penulis mendapati beberapa hadis, akan tetapi hadis yang akan menjadi pembahasan utama dalam penelitian ini adalah hadis riwayat Imam at-Tirmidzi No. 1155 Kitab 
Jurnal Riset Agama, Volume 1, Nomor 1 (April 2021): 157-166

Novi Nur Sholihat / Analisis Investasi Saham dalam Sistem Hukum Ekonomi Syariah: Sebuah Syarah Hadis Pendekatan Isu Kontemporer

Jual Beli Bab Dimakruhkan Jual Beli Apa yang Tidak Ada Padamu, sebagai berikut.

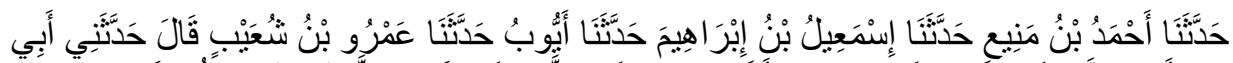

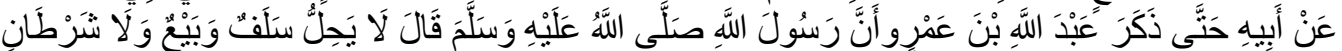

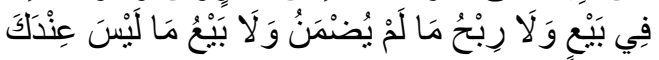

Telah menceritakan kepada kami Ahmad bin Mani' telah menceritakan kepada kami Isma'il bin Ibrahim telah menceritakan kepada kami Ayyub telah menceritakan kepada kami Amru bin Syu'aib ia berkata telah menceritakan kepada ayahku dari ayahnya hingga ia menyebut Abdullah bin Amru bahwa Rasulullah Saw bersabda, "Tidak halal menjual dan meminjam, tidak pula dua syarat dalam satu jual beli dan tidak halal laba terhadap barang yang tidak dapat dijamin (baik dan buruknya), serta tidak halal menjual apa yang tidak kamu miliki" (HR. Tirmidzi).

\section{Takhrij Hadis Investasi Saham dalam Islam}

Takhrij hadis terkait investasi saham dalam Islam ditampilkan dalam bentuk tabel berikut.

Tabel 1. Daftar Rawi Sanad

\begin{tabular}{|c|c|c|c|c|c|c|c|c|}
\hline \multirow[t]{2}{*}{ No. } & \multirow[t]{2}{*}{ Rawi Sanad } & \multicolumn{2}{|c|}{$\begin{array}{l}\text { Lahir/ } \\
\text { Wafat }\end{array}$} & \multirow[t]{2}{*}{ Negeri } & \multirow[t]{2}{*}{ Kunyah } & \multicolumn{2}{|c|}{ Komentar Ulama } & \multirow[t]{2}{*}{ Kalangan } \\
\hline & & L & W & & & - & + & \\
\hline 1 & $\begin{array}{l}\text { Abdullah } \\
\text { bin 'Amru } \\
\text { bin 'Ash bin } \\
\text { Wa'il }\end{array}$ & & $63 \mathrm{H}$ & Maru & $\begin{array}{l}\text { Abu } \\
\text { Muhammad }\end{array}$ & & $\begin{array}{l}\text { Ibnu Haja } \\
\text { al-Atsqalani: } \\
\text { Sahabat; } \\
\text { Adz } \\
\text { Dzahabi: } \\
\text { Sahabat }\end{array}$ & Sahabat \\
\hline 2 & $\begin{array}{l}\text { Muhammad } \\
\text { bin } \\
\text { 'Abdullah } \\
\text { bin 'Amru } \\
\text { bin al-'Ash }\end{array}$ & & & & & $\begin{array}{l}\text { Adz } \\
\text { Dzahabi: } \\
\text { Tidak } \\
\text { dikenal }\end{array}$ & $\begin{array}{l}\text { Ibnu Haja } \\
\text { al-Atsqalani: } \\
\text { Maqbul }\end{array}$ & $\begin{array}{l}\text { Tabi'in } \\
\text { kalangan } \\
\text { tua }\end{array}$ \\
\hline 3 & $\begin{array}{l}\text { Syu'aib bin } \\
\text { Abdullah } \\
\text { bin 'Amru } \\
\text { bin al-'Ash }\end{array}$ & & & Hijaz & & & $\begin{array}{l}\text { Ibnu } \\
\text { Hibban: } \\
\text { Tsiqah; Adz- } \\
\text { Dzahabi: } \\
\text { Shaduuq }\end{array}$ & $\begin{array}{l}\text { Tabi'in } \\
\text { kalangan } \\
\text { pertengah } \\
\text { an }\end{array}$ \\
\hline 4 & $\begin{array}{l}\text { Amru bin } \\
\text { Syu'aib bin } \\
\text { Muhammad } \\
\text { bin } \\
\text { Abdullah } \\
\text { bin 'Amru }\end{array}$ & & $\begin{array}{c}118 \\
\mathrm{H}\end{array}$ & $\begin{array}{l}\text { Marur } \\
\text { Rawdz }\end{array}$ & Abu Ibrahim & $\begin{array}{l}\text { Abu Daud: } \\
\text { Laisa bihujjah }\end{array}$ & $\begin{array}{l}\text { Al-'ajli: } \\
\text { Tsiqah; An- } \\
\text { Nasa'i: } \\
\text { Tsiqah; Ibnu } \\
\text { Hajar al- } \\
\text { 'asqalani: } \\
\text { Shaduuq }\end{array}$ & $\begin{array}{l}\text { Tabi'in } \\
\text { kalangan } \\
\text { biasa }\end{array}$ \\
\hline 5 & $\begin{array}{l}\text { Ayyub bin } \\
\text { Abi } \\
\text { Tamimah } \\
\text { Kaysan }\end{array}$ & & $\begin{array}{c}131 \\
\mathrm{H}\end{array}$ & Bashrah & Abu Bakar & & $\begin{array}{l}\text { Yahya bin } \\
\text { Ma'in: } \\
\text { Tsiqah; An- } \\
\text { Nasa'i: } \\
\text { Tsiqah tsabat; }\end{array}$ & $\begin{array}{l}\text { Tabi'in } \\
\text { kalangan } \\
\text { biasa }\end{array}$ \\
\hline
\end{tabular}


Jurnal Riset Agama, Volume 1, Nomor 1 (April 2021): 157-166

Novi Nur Sholihat / Analisis Investasi Saham dalam Sistem Hukum Ekonomi Syariah: Sebuah Syarah Hadis Pendekatan Isu Kontemporer

\begin{tabular}{|c|c|c|c|c|c|c|c|}
\hline & & & & & & $\begin{array}{l}\text { Muhammad } \\
\text { bin Sa'd: } \\
\text { Tsiqah tsabat; } \\
\text { Adz- } \\
\text { Dzahabi: } \\
\text { Imam }\end{array}$ & \\
\hline 6 & $\begin{array}{l}\text { Isma'il bin } \\
\text { Ibrahim bin } \\
\text { Muqsim }\end{array}$ & $\begin{array}{c}193 \\
\mathrm{H}\end{array}$ & Bashrah & Abu Bisyir & $\begin{array}{l}\text { Abu Daud: } \\
\text { “tidak ada } \\
\text { seorang } \\
\text { muhaddits } \\
\text { kecuali } \\
\text { melakukan } \\
\text { kesalahan, } \\
\text { kecuali Ibnu } \\
\text { 'Ulaiyah dan } \\
\text { Bisyr bin al } \\
\text { Mufadldlal; } \\
\text { As-Saji: } \\
\text { Perlu } \\
\text { dikoreksi } \\
\text { ulang; Ibnu } \\
\text { Hajar al- } \\
\text { 'Asqalani: } \\
\text { Dhaif; Adz- } \\
\text { Dzahabi: } \\
\text { Dhaif }\end{array}$ & $\begin{array}{l}\text { Syu'bah: } \\
\text { Sayyidul } \\
\text { Muhadditsin; } \\
\text { Yahya bin } \\
\text { Ma'in: } \\
\text { Tsiqah } \\
\text { ma'mun; } \\
\text { Muhammad } \\
\text { Sa'd: Tsigah } \\
\text { tsabat hujjah; } \\
\text { Abdurrahm } \\
\text { an bin } \\
\text { Mahdi: Dia } \\
\text { lebih kuat } \\
\text { dari } \\
\text { Husyaim; } \\
\text { Yahya bin } \\
\text { Said: Lebih } \\
\text { kuat } \\
\text { daripada } \\
\text { Wuhaib }\end{array}$ & $\begin{array}{l}\text { Tabi'ut } \\
\text { Tabi'in } \\
\text { kalangan } \\
\text { pertengah } \\
\text { an }\end{array}$ \\
\hline 7 & $\begin{array}{l}\text { Ahmad bin } \\
\text { Mani' bin } \\
\text { Abdur } \\
\text { Rahman }\end{array}$ & $\begin{array}{c}244 \\
\mathrm{H}\end{array}$ & $\begin{array}{l}\text { Baghda } \\
\text { d }\end{array}$ & Abu Ja'far & & $\begin{array}{l}\text { An-Nasa'i: } \\
\text { Tsiqah; } \\
\text { Maslamah } \\
\text { bin Qasim: } \\
\text { Tsiqah; Ad- } \\
\text { Daruquthni: } \\
\text { La ba'sa bih; } \\
\text { Ibnu } \\
\text { HIbban: } \\
\text { Disebutkan } \\
\text { dalam 'ats } \\
\text { tsiqaat; Ibnu } \\
\text { Hajar al- } \\
\text { 'Asqalani: } \\
\text { Tsiqah hafidz }\end{array}$ & $\begin{array}{l}\text { Tabi'ul } \\
\text { Atba' } \\
\text { kalangan } \\
\text { tua }\end{array}$ \\
\hline 8 & $\begin{array}{l}\text { Imam at- } \\
\text { Tirmidzi }\end{array}$ & $\begin{array}{c}279 \\
\mathrm{H}\end{array}$ & Tirmiz & Abu 'Isa & & Imam Hadis & Mudawwin \\
\hline
\end{tabular}

Tabel 1 merupakan rawi dan sanad hadis riwayat Imam at-Tirmidzi No. 1155 terkait investasi saham dalam Islam. Hadis ini diriwayatkan oleh 8 (delapan) orang rawi berawal dari sahabat sampai mudawwin. Semua rawi tidak diketahui tahun lahirnya. Sebanyak 2 (dua) orang rawi tidak diketahui tahun wafat dan kuniyahnya, yaitu Muhammad bin 'Abdullah bin 'Amru bin al-'Ash dan Syu' aib bin Abdullah bin 'Amru bin al-'Ash. Ssatu orang rawi tidak diketahui negerinya, yaitu Muhammad bin 'Abdullah bin 'Amru bin Al 'Ash. Rawi pertama hadis ini adalah Abdullah bin 'Amru bin 'Ash bin Wa'il. Sedangkan sanad pertama dari hadis ini adalah Imam at-Tirmidzi. Berdasarkan Ilmu Hadis rawi pertama merupakan sanad terakhir sedangkan rawi terakhir merupakan sanad pertama (Darmalaksana, 2021b). 
Jurnal Riset Agama, Volume 1, Nomor 1 (April 2021): 157-166

Novi Nur Sholihat / Analisis Investasi Saham dalam Sistem Hukum Ekonomi

Syariah: Sebuah Syarah Hadis Pendekatan Isu Kontemporer

\section{Kualitas Hadis Investasi Saham dalam Islam}

Syarat hadis dinilai berkualitas sahih bila rawi adil dan dhabit, sanad bersambung (muttasil), matan hadis tidak janggal, dan matan hadis tidak cacat (Darmalaksana, 2020d). Komentar ulama beragam mencakup penilaian negatif (jarh) dan positif ( $t a^{\prime} d i l$ ) (Darmalaksana, 2021b). Pada tabel 1 tampak adz-Dzahabi menilai Muhammad bin 'Abdullah bin 'Amru bin al-'Ash sebagai tidak dikenal, Abu Daud menilai Amru bin Syu'aib bin Muhammad bin Abdullah bin 'Amru sebagai laisa bihujjah, Abu Daud menilai Isma'il bin Ibrahim bin Muqsim sebagai tidak ada seorang muhaddits kecuali melakukan kesalahan, kecuali Ibnu 'Ulaiyah dan Bisyr bin al Mufadldlal, as-Saji menilai Isma'il bin Ibrahim bin Muqsim sebagai perlu dikoreksi ulang, dan Ibnu Hajar al-'Asqalani dan adz-Dzahabi menilai Isma'il bin Ibrahim bin Muqsim sebagai Dhaif. Dengan demikian, rawi pada jalur sanad ini tidak seluruhnya adil dan dhabit yang dapat mempengaruhi nilai rendah kualitas hadis. Sedangkan syarat sanad bersambung adalah bertemu (liqa') antara guru yaitu penyampai hadis dan murid yakni penerima hadis (Darmalaksana, 2021b). Pertemuan guru dan murid dapat diketahui dari masa waktu dan negeri (Darmalaksana, 2021b). Masa waktu dilihat dari tahun lahir dan wafat dan negeri dapat menunjukan pertemuan guru dan murid di satu wilayah (Darmalaksana, 2021b). Apabila beberapa periwayat tidak diketahui tahun lahir dan wafat, maka para rawi dapat diasumsikan rata-rata berusia kurang lebih 90 tahun (Darmalaksana, 2021b). Meskipun pada Tabel 1 semua periwayat tidak diketahui tahun lahir dan ada beberapa yang tidak diketahui tahun wafat, namun dengan asumsi tersebut maka para periwayat pada jalur sanad Tabel 1 diperkirakan bertemu antara guru dan murid. Dengan kata lain, sanad hadis pada Tabel 1 dapat dikatakan bersambung (Darmalaksana, 2021b).

Kualitas hadis memungkinkan naik derajatnya melalui i'tibar yaitu adanya syahid dan muttabi (Darmalaksana, 2021b). Syahid adalah hadis lain sedangkan muttabi ialah periwayat lain (Mardiana \& Darmalaksana, 2020). Berdasarkan penelusuran ditemukan bahwa hadis riwayat Imam atTirmidzi No. 1155 dijumpai pula pada hadis riwayat Imam an-Nasa'i No. 4532 (Saltanera, 2015) sebagai berikut.

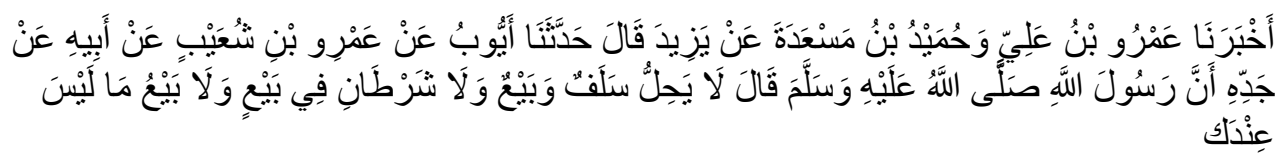

Telah mengabarkan kepada kami 'Amru bin Ali dan Humaid bin Mas'adah dari Yazid, ia berkata: telah menceritakan kepada kami Ayyub dari 'Amru Syu'aib dari ayahnya dari kakeknya bahwa Rasulullah Saw 
Jurnal Riset Agama, Volume 1, Nomor 1 (April 2021): 157-166

Novi Nur Sholihat / Analisis Investasi Saham dalam Sistem Hukum Ekonomi

Syariah: Sebuah Syarah Hadis Pendekatan Isu Kontemporer

bersabda, "Tidak halal jual beli dengan syarat diberi utang, serta dua syarat dalam jual beli serta menjual apa yang tidak kamu miliki" (an-Nasa'i).

Hadis riwayat Imam an-Nasa'i No. 4532 di atas, berposisi menjadi syahid dan muttabi bagi hadis riwayat imam at-Tirmidzi No. 1155. Status hadis riwayat at-Tirmidzi No. 1155 adalah dhaif karena terdapat komentar ulama yang memberikan penilaian negatif terhadap beberapa periwayat. Namun terdapat syahid dan muttabi dari hadis riwayat Imam an-Nasa'i No. 4532 sehingga yang semula dhaif maka naik derajatnya menjadi hasan $l i$ ghairihi. Sejalan dengan ini, Muhammad Nashiruddin al-Albani menilai kualitas hadis riwayat Imam at-Tirmidzi No. 1155 dengan status hasan shahih (Saltanera, 2015).

\section{Syarah Hadis Investasi Saham dalam Islam}

Syarah hadis meliputi penjelasan redaksi hadis guna diperoleh pemahaman bagi pengalaman hadis (Darmalaksana, 2020c). Hadis dapat diamalkan ( $\left.m a^{\prime} m u l\right)$ apabila hadis tersebut diterima (maqbul) melalui takhrij (Darmalaksana, 2021b). Berdasarkan takhrij ditemukan status hadis riwayat Imam at-Tirmidzi No. 1155 berkualitas hasan li ghairihi dari sisi persambungan sanad dan penilaian rawi. Selebihnya, syarat hadis dapat diterima dan dapat diamalkan bila matan hadis tidak janggal dan tidak cacat (Darmalaksana, 2021b).

Hadis riwayat Imam at-Tirmidzi No. 1155 menceritakan bahwa haram menjual dan meminjamkan, dua syarat dalam satu jual beli, laba terhadap barang yang tidak dapat menjamin baik dan buruknya, dan menjual apa yang tidak dimiliki. Sedangkan hadis riwayat Imam an-Nasa'i No. 4532 menceritakan bahwa haram jual beli dengan syarat diberi utang, dua syarat dalam jual beli, dan menjual apa yang tidak dimiliki.

Nabi Muhammad Saw. dalam menjalankan bisnisnya senantiasa memperkaya dirinya dengan kejujuran, keteguhan memegang janji, dan sifat-sifat mulia lainnya, sampai dijuluki sebagai orang terpercaya (alAmin). Para pemilik modal di Mekkah semakin banyak yang membuka peluang kemitraan dengan Nabi Saw. salah seorang pemilik modal tersebut adalah Khadijah yang menawarkan kemitraan berdasarkan mudarabah (bagi hasil). Dalam hal ini, khadijah bertindak sebagai sahib al-mal (pemilik modal) dan Nabi Muhammad Saw. sebagai mudarib (pengelola) (Antonio, 2007). Dengan demikian Nabi Muhammad Saw. memasuki dunia bisnis dan perdagangan dengan cara menjalankan modal orang lain (investor), baik dengan upah (fee based) maupun dengan sistem bagi hasil (profit sharing) (Antonio, 2007). Praktik investasi sudah ada sejak Nabi Muhammad Saw. bahkan beliau secara langsung terjun dalam praktik bisnis dan investasi. Beliau memberikan contoh bagaimana mengelola investasi hingga menghasilkan keuntungan banyak. Hal ini tidak terlepas 
Jurnal Riset Agama, Volume 1, Nomor 1 (April 2021): 157-166

Novi Nur Sholihat / Analisis Investasi Saham dalam Sistem Hukum Ekonomi

Syariah: Sebuah Syarah Hadis Pendekatan Isu Kontemporer

dari pengalaman beliau yang lama sebagai pedagang dan pengelola bisnis (mudarib) (Pardiansyah, 2017).

Status hadis riwayat Imam at-Tirmidzi No. 1155 berkualitas hasan li ghairihi, baik sanad maupun matan. Dengan demikian, hadis ini maqbul dan ma'mul bih bagi amalan Islam (Darmalaksana, 2021b). Namun demikian, semua bentuk investasi pada dasarnya boleh dilakukan sampai ada dalil yang melarangnya, yaitu apabila ditemukan kegiatan terlarang dalam suatu kegiatan bisnis, baik objek maupun caranya (prosesnya), yaitu kegiatan yang mengandung gharar, maysir, riba, tadlis, talaqqi rukban, taghrir, ghabn, darar, risywah, maksiat dan zalim.

\section{Kesimpulan}

Nabi Saw. mengajarkan investasi dengan kejujuran, keteguhan memegang janji, dan sifat-sifat lainnya sampai dijuluki sebagai orang terpercaya (al-Amin). Status hadis tentang investasi saham dalam Islam berkualitas hasan li ghairihi, baik sanad maupun matan. Sehingga hadis ini maqbul dan otomatis ma'mul bih bagi amalan muslim. Investasi merupakan kegiatan yang dianjurkan dalam pandangan Islam. Hal ini karena kegiatan investasi sudah dilakukan oleh Nabi Muhammad Saw. sejak muda sampai menjelang kerasulan. Selain itu, akan tercapainya mashlahah multiplayer effect, di antaranya terciptanya lapangan usaha dan lapangan pekerjaan, menghindari dana mengendap, dan agar dana tersebut tidak berputar di antara orang kaya saja. Namun, apabila ditemukan kegiatan terlarang dalam kegiatan investasi, baik objek maupun caranya (prosesnya), maka investasi tersebut dilarang. Penelitian ini diharapkan memiliki implikasi manfaat bagi yang melakukan investasi saham. Penelitian ini memiliki keterbatasan yakni kurangnya penguasaan terhadap ilmu hadis maupun ilmu ekonomi dan bisnis. Sehingga diperlukan penelitian lebih lanjut, terutama dari segi takhrij berikut analisis sesuai dengan isu kontemporer. Penelitian ini merekomendasikan agar adanya kolaborasi penelitian lebih lanjut antara peminat ilmu hadis dan ilmu ekonomi bisnis untuk meneliti terkait investasi saham dari segi objek dan proses jika ingin berinvestasi saham yang sesuai dengan tuntunan ajaran Islam.

\section{Daftar Pustaka}

Arrazaq, N. A. (2020). Investasi Syariah dalam Rangka Menegakkan Prinsip Syariah. Journal of Islamic Law Studies, 1-18.

Darmalaksana, W. (2018). Paradigma Pemikiran Hadis. JAQFI: Jurnal Aqidah Filsafat UIN SGD Bandung, 2 (1).

Darmalaksana, W. (2020a). Formula Penelitian Pengalaman Kelas Menulis. Kelas Menulis UIN Sunan Gunung Djati Bandung, 1-8. 
Jurnal Riset Agama, Volume 1, Nomor 1 (April 2021): 157-166

Novi Nur Sholihat / Analisis Investasi Saham dalam Sistem Hukum Ekonomi

Syariah: Sebuah Syarah Hadis Pendekatan Isu Kontemporer

Darmalaksana, W. (2020b). Metode Penelitian Kualitatif Studi Pustaka dan Studi Lapangan. Pre-Print Digital Library UIN Sunan Gunung Djati Bandung, 1-6.

Darmalaksana, W. (2020c). Penelitian Hadis Metode Syarah Pendekatan Kontemporer: Sebuah Panduan Skirpsi, Tesis, dan Disertasi. Diroyah: Jurnal Studi Ilmu Hadis, 5, 58-68.

Darmalaksana, W. (2020d). Prosiding Proses Bisnis Validitas Hadis untuk Perancangan Aplikasi Metode Tahrij. Jurnal Ushuluddin UIN Sunan Gunung Djati Bandung, 1-7.

Darmalaksana, W. (2021a). Herbal Tumbuhan Senna dalam Pengobatan Infeksi Covid-19: Studi Takhrij dan Syarah Hadis. Pre-Print Kelas Menulis UIN Sunan Gunung Djati Bandung, 1-11.

Darmalaksana, W. (2021b). Kosmetik Halal sebagai Lifestyle untuk Kesehatan: Studi Takhrij dan Syarah Hadis.

Darmalaksana, W., \& Qomaruzzaman, B. (2020). Teolologi Terapan dalam Islam : Sebuah Syarah Hadis dengan Pendekatan High Order Thinking Skill. Khazanah Theologia 2 (3), 119-131.

Hartati, N. (2021). Investasi Saham Syaria di Bursa Efek Indonesia dalam Perspektif Hukum Ekonomi Syariah. Jurnal Hukum Ekonomi Syariah 5 (01), 31-48.

Nadiran, H. (2014). Kritik Sanad Hadis: Telaaah Metodologis. Jurnal Ilmu Agama: Mengkaji Doktrin, Pemikiran, Dan Fenomena Agama, 15 (1).

Pardiansyah, E. (2017). Investasi dalam Perspektif Ekonomi Islam: Pendekatan Teoritis dan Empiris. Ecomonica: Jurnal Ekonomi Islam, 337-373.

Ridwan, M., Umar, M. H., \& Ghafar, A. (2021). Sumbe-sumber Hukum Islam dan Implementasinya (Kajian Deskriptif Kualitatif tentang AlQuran, Sunnah, dan Ihma'). Borneo: Journal of Islamic Studies, 1 (2), 2841.

Saltanera. (2015). Ensiklopedia Hadis 9 Imam. In. Lembaga Ilmu dan Dakwah Publikasi Sarana Keagamaan, Lidwa Pusaka.

Selasi, D. (2018). Ekonomi Islam: Halal dan Haramnya Berinvestasi Saham Syaria. Jurnal Ekonomi Syariah dan Bisnis 1 (2), 87-96. 